Article

\title{
Implementation of the Low-Voltage Ride-Through Curve after Considering Offshore Wind Farms Integrated into the Isolated Taiwan Power System
}

\author{
Shiue-Der Lu ${ }^{1}{ }^{(}$, Meng-Hui Wang ${ }^{1, *}$ and Chung-Ying Tai ${ }^{2}$ \\ 1 Department of Electrical Engineering, National Chin-Yi University of Technology, Taichung 41170, Taiwan; \\ SDL@ncut.edu.tw \\ 2 Department of Electrical Engineering National Taiwan University of Science and Technology, \\ Taipei 10607, Taiwan; 40125147@gm.nfu.edu.tw \\ * Correspondence: wangmh@ncut.edu.tw; Tel.: +886-4-23924505 (ext. 7233)
}

Received: 3 March 2019; Accepted: 27 March 2019; Published: 1 April 2019

\begin{abstract}
In response to the power impact effect resulting from merging large-scale offshore wind farms (OWFs) into the Taiwan Power (Taipower) Company (TPC) system in the future, this study aims to discuss the situation where the offshore wind power is merged into the power grids of the Changbin and Changlin areas, and study a Low-Voltage Ride-Through (LVRT) curve fit for the Taiwan power grid through varying fault scenarios and fault times to reduce the effect of the tripping of OWFs on the TPC system. The Power System Simulator for Engineering (PSS/E) program was used to analyze the Taipower off-peak system in 2018. The proposed LVRT curve is compared to the current LVRT curve of Taipower. The research findings show that if the offshore wind turbine (OWT) set uses the proposed LVRT curve, when a fault occurs, the wind turbines can be prevented from becoming disconnected from the power grid, and the voltage sag amplitude of the connection point during the fault and the disturbances after the fault is cleared are relatively small. In addition, according to the transient stability analysis results, the system can return to stability after fault clearance, thereby meeting the Taipower transmission system planning criteria and technical key points of renewable energy power generation system parallel connection technique.
\end{abstract}

Keywords: large-scale offshore wind farms (OWFs); Taiwan Power Company (TPC); low-voltage ride-through; power system simulator for engineering; renewable energy

\section{Introduction}

With the rise of environmental considerations and the growth of renewable technology, various countries' energy strategies have proposed increasing the ratio of renewable energy in succession to decrease their dependence on thermal power plants. As wind power technology has gradually developed and the generating efficiency thereof is currently greater than that of other renewable energy sources, it has become one of the most important parts of the green energy mixes developed by various countries in recent years. According to the annual research report of GWEC, the installed global wind power generation capacity was $539 \mathrm{GW}$ up to 2017, and the newly installed wind power capacity in 2017 was as high as 52 GW [1].

The Taiwanese government has proposed a four-year (2017-2020) promotion project for wind power generation to increase Taiwan's accumulated OWF capacity to 520 MW by 2020. Taiwan's plan is to promote the development of large-scale OWFs through economies of scale, eventually expanding its offshore wind power capacity to $3000 \mathrm{MW}$ [2]. Therefore, comprehensive standard operating procedures (SOPs) on grid connection, research on the quality of power grids, and response strategies 
for the plan are required to guarantee the successful integration of wind farms with established power grids and to reduce the impact on power grids caused by the integration of renewable energy. SOPs for integrating renewable energy with power grids have been established in European and North American countries, where wind power is flourishing. In particular, Low-Voltage Ride-Through has become a key topic for wind power research.

Regarding power system dispatching, when wind power capacity reaches a certain high proportion of the total generating capacity of an entire power grid system, power generation instability can affect the operation of the entire grid system. In particular, if accidents or disturbances occur in the mains supply, causing a voltage sag at the point of common coupling (PCC) in the wind farms, then curtailment from the PCC may cause an instantaneous, massive drop of power in the system. Consequently, the power system stability can be upset, leading to a sudden imbalance between power demand and power generation in the power supply system, a massive variation in the mains supply frequency, and even the collapse of the entire system [3,4]. Therefore, several studies have proposed to mitigate the power quality issues due to high penetration of renewable energy sources in electric grid systems [5-8]. In [5], two control techniques were used to different reactive power values of loads and varying scenarios of distributed generation unit positions in order to control the angle between the current and voltage for improving the voltage profile and reducing the power losses. In [6], a useful emergency energy system was designed for Latakia city to ensure that the system would be steady and able to support most of the requirements of the city. In [7], an advanced control strategy combined with time-varying gains of two control loops was presented to enhance frequency regulation in an actual power system. In [8], a stable inertial control program was presented by using spatially dependent gains to enhance the frequency nadir and confirming stable operation of wind turbines.

In addition, LVRT issues have played an increasingly important role in many countries developing renewable energy in recent years. Therefore, an appropriate LVRT curve must be implemented to guarantee that wind power generators remain operational without trips for a specified period of time, even when faults occur in the power system. According to the key point, as determined by Taipower Company, the wind power equipment are merged into a voltage system (greater than $25 \mathrm{kV}$ and less than $345 \mathrm{kV}$ ) with LVRT capability, thus, when the power system fails, inducing a PCC voltage sag, the wind power generation equipment must be able to run continuously [9]. Only the reverse power transmission and voltage regulation factor were updated and LVRT was not discussed while the new edition of the key points was published in 2016. The formulation of the curve refers to the first LVRT grid connection requirement of the world, as presented by TenneT transmission system operator (TSO) $\mathrm{GmbH}$ (formerly known as E.ON Netz GmbH) in 2003 [10-15]. However, the power transmission guidelines of Germany proposed a newer version of LVRT according to the features of wind turbines as well as a power grid, and put it in the grid connection specifications. Therefore, Taiwan's power experts and scholars have suggested revising and enhancing the LVRT curve and the fault ride-through clauses of wind turbines in the existing renewable energy grid connection technology code of Taipower, in order to require large-scale renewable energy power plants to enhance equipment performance to improve the steady running ability.

In terms of the present studies considering LVRT after the wind turbines are added to the system, since TenneT proposed the first LVRT curve, some countries with developed wind power have presented LVRTs meeting their power grid characteristics in succession. Reference [14] describes the LVRT requirements of Canada, the United Kingdom, and Denmark. Reference [15] is the LVRT formulated by the state grid of the United Kingdom, which is applied to power systems with a voltage class higher than $200 \mathrm{kV}$; regardless of whether the fault is balanced or unbalanced, as long as the fault duration does not exceed 0.14 seconds, even if the voltage drops to $0 \%$ of voltage before the fault occurrence, not all wind turbines can be disconnected from the system. The wind turbines can be disconnected from the power system when the fault duration exceeds 0.14 seconds, and the fault severity is under the curve. References $[16,17]$ indicate that the wind turbine working voltage classes in Denmark are divided into below $100 \mathrm{kV}$ and above $100 \mathrm{kV}$. When the system has a serious 
fault, including a three-phase short-circuit fault continuing 0.1 second, a two-phase short-circuit fault continuing 0.1 second, and a short-circuit fault continuing 0.1 second within $0.3-0.5$ seconds, meaning more than two two-phase short-circuit faults within two minutes, the wind turbines need not be linked to the power system.

The Canadian LVRT, developed by the power companies of Alberta and Quebec, is described in [18]. The LVRT proposed by Quebec is also referred to as the Hydro-Quebec curve, and it is applicable for three-phase balance or imbalance faults at PCC regardless of the locations of the fault points in the system. In [19], the DIgSILENT software was used to create a grid system coupled with permanent magnet generator (PMG) wind turbine systems and doubly-fed induction generators (DFIGs) to simulate the transient responses and low-voltage capability of these two types of generators when encountering faults in the system. In [20], a dynamic simulation was conducted on the OWFs of various collector system topologies during system faults, and the fault endurance of the wind farms and individual wind turbines on the LVRT capability curve was compared. In [21], approaches to improve LVRT capability, such as increases in rotor impedance, choppers, and arc suppression circuits, were employed to explore their effects on wind turbines. The LVRT characteristics of wind turbines were examined in [22], which focused on the direct current capacitor voltage of the transducer in a DFIG; the time from the fault occurrence to the point when the system voltage exceeded its limiting value was identified to define the LVRT applicable for the DFIG. To sum up, there are no studies regarding the formulation and revision of Taiwan's power grid LVRT curve. Therefore, this paper aims at the present Taipower system, and studies a LVRT curve fit for wind turbines according to different fault scenarios and fault times after a $520 \mathrm{MW}$ offshore wind generating set is merged into Taipower. As Taiwan is an isolated island power system, which is special, and considering the present green energy development planning, wind power objectives, and enhancement of the grid connection level, the single unit installed capacity and the overall wind farm capacity are increased, the main failure type is complex, and power grid accident cases have exceeded the existing LVRT, the operation and safety of the power grid system with wind power are influenced, thus, it is necessary to discuss and revise the present LVRT curve.

\section{Introduction to Simulation of Taipower and Grid Connection Systems}

The OWFs and onshore substations in the coastal area of Changbin are discussed and the actual off-peak system of Taiwan's power grid in 2018 is analyzed. Based on the 36 potential offshore sites and the existing sea area opened in the offshore wind power generation planning site application operation key points, the total development potential is estimated at about $23 \mathrm{GW}$ [23], 25 sites are concentrated in Yun-Chang Rise area, as shown in Figure 1, the offshore blocks in the area are relatively concentrated, and the scale of each block exceeds $200 \mathrm{MW}$.

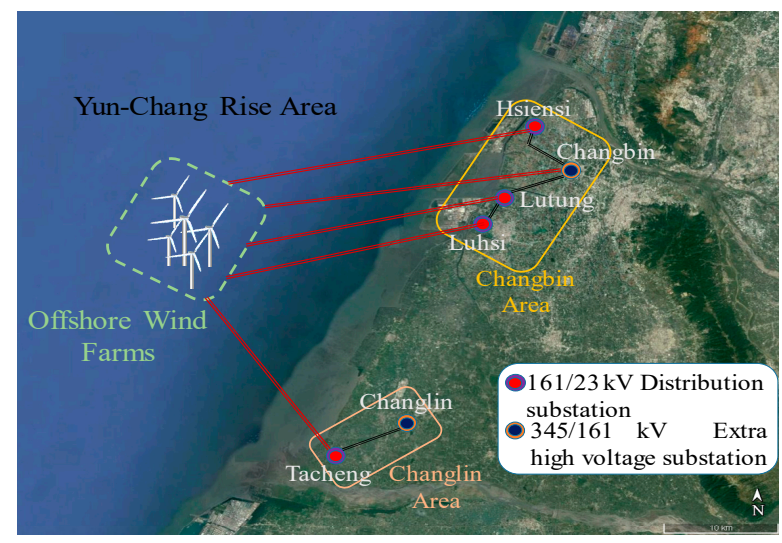

Figure 1. Graph showing the location of substations along the Changlin and Changbin areas. 


\subsection{Introduction to Changlin Areas and Power Grid in Changbin}

The Lutung, Luhsi, Hsienhsi, Changbin, and Tacheng substations in the Changlin and Changbin areas are chosen as the OWFs' landing connection points, as shown in Figure 1.

In the case of wind turbines merged into various substations, transient stability, voltage fluctuation, and three-phase short-circuit fault are carried out. Finally, a LVRT curve suitable for merging wind turbines into the Taiwan power system is formulated based on the simulation results.

The wind turbines adopted in this study were GEWT 4.0 MW full scale converter fed induction generators, which are manufactured by the General Electric Company (Boston City, USA) and feature a maximal output of $4 \mathrm{MW}$ each (Figure 2). These turbines, which are variable-speed models and feature a wide range of rotor speeds, were connected to transformers through converters before being coupled with the power grids; these converters can be used for reactive power regulation [24].

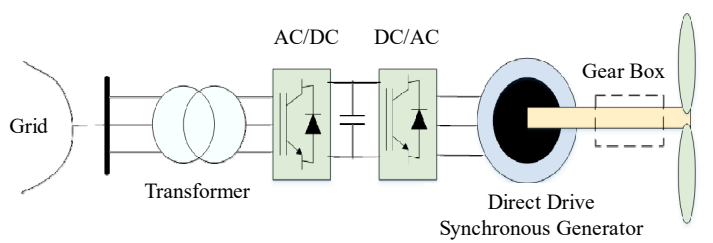

Figure 2. Diagram of a full scale converter-fed induction generator.

\subsection{Inside Grid Connection Configuration of OWFs in Chang-Yuen Rise Area}

Blocks of large-scale wind farms were defined for the inside framework of the simulated offshore area. Each of the five blocks featured 26 wind turbines with a wind power capacity of $104 \mathrm{MW}$, giving a total capacity of $520 \mathrm{MW}$. Each generator wind turbine had its voltage raised from $0.69 \mathrm{kV}$ to $33 \mathrm{kV}$ through an internal boost transformer. Each block was coupled with a main bus and had its voltage increased from $33 \mathrm{kV}$ to $161 \mathrm{kV}$ through an offshore substation. The power was then transmitted to the land substations through $161-\mathrm{kV}$ submarine cables.

As shown in Figure 3, four of the offshore blocks were connected to the Changbin H (2301), Hsienhsi H (5801), Lutung H (5801), and Luhsi H (5811) substations, and the remaining block was connected to the Tacheng H (5841) substation.

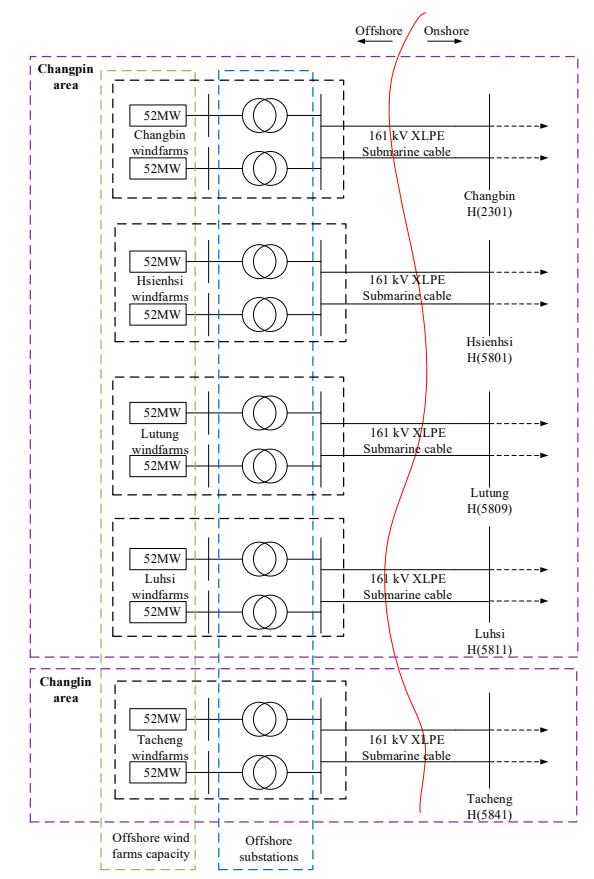

Figure 3. Graph of connecting the offshore wind farm blocks into the land distribution substations. 


\section{LVRT Curve Program of Meeting OWFs into Taipower System}

In this study, the PSS/E power analysis program (Siemens, Berlin, Germany) was employed for our LVRT simulation, including power flow analysis, transient stability analysis, fault analysis, etc. In addition, the actual system parameters in Taiwan and the off-peak system in the coastal area of Changbin in 2018 were utilized. In order to obtain practical analysis results, a series of conditions need to be considered. The system is free of new (expanded) transmission lines, $\mathrm{N}-1$ and $\mathrm{N}-2$ planning criteria are used, the systems under different fault scenarios and fault times are compared, the system power flow is simulated, and the minimum voltage, transient stability, and three-phase short-circuit fault of wind turbines during the fault are analyzed. Finally, a wind turbine LVRT standard is formulated according to the simulation results to avoid the trip of OWTs influencing the Taipower system.

According to the requirements of technical key points, when the voltage at the OWT connection point is $15 \%$ of the rated voltage, the OWTs shall be capable of keeping the grid connected for at least 0.5 seconds, and the wind power generation equipment shall be grid connected for at least 3 seconds when the voltage is recovered to $90 \%$ of the rated voltage [9].

According to the simulation results in Table 1, when the onshore bus fails, the terminal voltage of OWTs is close to 0 p.u., thus, in terms of the proposed LVRT curve, the OWTs shall be able to connect the grid within a time range.

Table 1. The OWTs Minimum Voltage during a fault.

\begin{tabular}{ccc}
\hline Fault Location & Tripping of Transmission Line & Minimum Voltage of the OWTs \\
\hline Changbin & Changbin H (2301)-Tsaokang \#A (7710) & Changbin Windfarms $/ 0.032$ p.u. \\
Hsienhsi & Hsienhsi H (5801)-Changbin H (2301) & Hsienhsi Windfarms $/ 0.032$ p.u. \\
Lutung & Lutung H (5809)-Luhsi H (5811) & Lutung Windfarms $/ 0.032$ p.u \\
Luhsi & Luhsi H (5811)-Lutung H (5809) & Luhsi Windfarms $/ 0.032$ p.u \\
Tacheng & Tacheng H (2321)-Changlin H (2321) & Tacheng Windfarms $/ 0.031$ p.u. \\
\hline
\end{tabular}

The longer the fault clearing time, the longer the stable voltage recovery time. The voltage may even break down if the fault clearing time is too long, and cannot recover to a steady state. Therefore, it is necessary to consider whether the voltage at the OWT connection point can recover its stability during a fault when formulating the LVRT curve. The simulated fault time is increased to 0.625 seconds in this paper, the voltage variation at the wind turbine end is observed, and the current LVRT, as specified by Taipower, is followed after 0.625 seconds. The $\mathrm{A} \rightarrow \mathrm{B} \rightarrow \mathrm{F} \rightarrow \mathrm{I}$ in Figure 4 is the Taipower specified wind turbine LVRT; $\mathrm{A} \rightarrow \mathrm{C} \rightarrow \mathrm{D} \rightarrow \mathrm{E} \rightarrow \mathrm{G} \rightarrow \mathrm{H} \rightarrow \mathrm{I}$ is the proposed LVRT in this paper. The simulation process is described as follows:

$>\mathrm{A} \rightarrow \mathrm{C}$ : When a severe three-phase short circuit happens in the system, the voltage falls to 0 p.u.

$>C \rightarrow$ D: When a fault occurs at one of the spots in the system, during the fault clearance time, the voltage of the wind turbines at PCC recovers to $90 \%$ of the rated voltage in 3 seconds; no turbines can be decoupled from the grids during the 3 seconds of voltage recovery regardless of the magnitudes of their voltage sags.

$>$ E $\rightarrow$ G: The minimum voltages of the turbines when disturbances occurred at various fault durations were simulated.

$>\mathrm{G} \rightarrow \mathrm{H} \rightarrow \mathrm{I}$ : The TPC LVRT curve was retained.

The voltage will drop to $0(\mathrm{~A} \rightarrow \mathrm{C})$ when the three-phase short-circuit fault occurs in the power system, and the $\mathrm{G} \rightarrow \mathrm{H} \rightarrow \mathrm{I}$ maintains the original LVRT curve established by Taipower Company. Therefore, the subsequent simulation analysis lays stress on how to make the value of point $\mathrm{D}$ and the values of point $\mathrm{E}$ to point $\mathrm{G}$ by simulation analysis (Figure 4 ). 


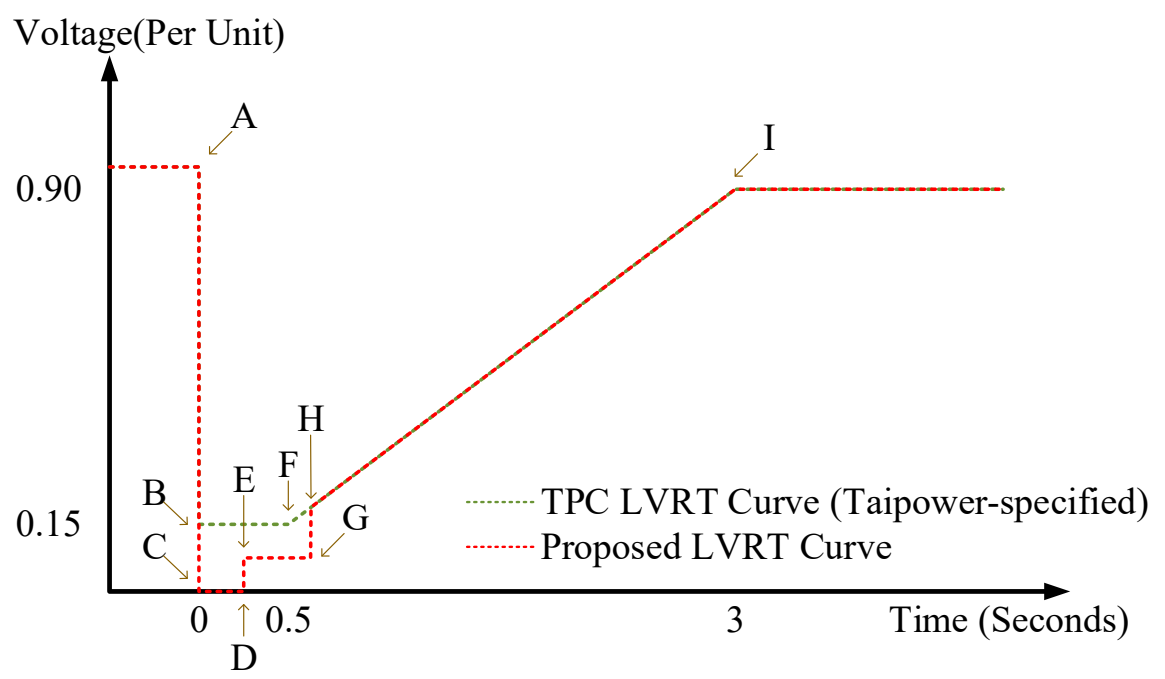

Figure 4. The proposed LVRT curve versus TPC LVRT curve.

\subsection{Establishment of the Value of Point D-Fult Cearing Tme of Ofshore Wnd Frms at Dfferent Fult Pints}

This subsection simulates a three-phase short-circuit fault in the $161 \mathrm{kV}$ and $345 \mathrm{kV}$ buses of an adjacent offshore wind farm with different line trip accidents, in order to determine whether the OWTs will recover to $90 \%$ within 3 seconds after the fault. The trip line follows the TPC transmission system planning criteria, the extra-high voltage cable uses N-2 criteria in the $345 \mathrm{kV}$ transmission line, thus, the non-fault end is cleared by four cycles when a three-phase short-circuit fault occurs in the line, and the critical clearing time of fault end is higher than 4.5 cycles. A non-extra high voltage cable uses N-1 criteria at the extra-high voltage substation (E/S). In terms of the $161 \mathrm{kV}$ transmission line, if the renewable energy grid-connected installed capacity exceeds $420 \mathrm{MW}$, the N-1 criteria are used (a three-phase short-circuit fault), the non-fault end is cleared by seven cycles, and the fault critical clearing time is higher than 12 cycles [25].

Table 2 lists the 19 fault scenarios, 10 of which occurred in the $161-\mathrm{kV}$ circuit and nine in the 345-kV circuit.

Table 2. Codes of the fault scenarios.

\begin{tabular}{|c|c|c|c|}
\hline \multicolumn{2}{|c|}{ Fault Scenario } & \multirow{2}{*}{$\begin{array}{l}\text { Fault Location } \\
\text { Luhsi H (5811) }\end{array}$} & Tripping of Transmission Line \\
\hline \multirow{10}{*}{$161 \mathrm{kV}$} & Fault 1 & & Luhsi H(5811)-Lutung H (5809)1st line \\
\hline & Fault 2 & Changbin H (2301) & Changbin H(2301)-Tsaokang \#A (7710) 1st line \\
\hline & Fault 3 & Hsienhsi H (5801) & Hsienhsi H(5801)-Changbin H (2301) 1st line \\
\hline & Fault 4 & Lutung H (5809) & Lutung H(5809)-Luhsi (5811) H 1st line \\
\hline & Fault 5 & Hanpao H (5817) & Hanpao H(5817)-Tsaokang \#B (7711) 2nd line \\
\hline & Fault 6 & Chuanhsiang H (2351) & Chuanhsiang H(2351)-Changhsin \#A (7750) Rth line \\
\hline & Fault 7 & Fuhsiang H (5855) & Fuhsiang H(5855)-Changhua H (3551) 1st line \\
\hline & Fault 8 & Tsaokang H(5819) & Tsaokang H(5819)-Tsaokang \#B (7711) 2nd line \\
\hline & Fault 9 & Tacheng H (5841) & Tacheng H (5841)-Changlin H (2321) 1st line \\
\hline & Fault 10 & Changhsin H (5851) & Changhsin H (5851)-Changhsin \#A (7750) Rth line \\
\hline \multirow{9}{*}{$345 \mathrm{kV}$} & Fault 11 & Houli E (2130) & Houli E (2130)-Omei E (2000) Wth \& Rth line \\
\hline & Fault 12 & Chunghuopei E (530) & Chunghuopei E (530)-Chungkang E (2150) Nth \& Sth line \\
\hline & Fault 13 & Changbin E (2300) & Changbin E (2300)-Chuanhsiang E (2350) 1st line \\
\hline & Fault 14 & Changlin E (2320) & Changlin E (2320)-Nantou E (2400) Nth line \\
\hline & Fault 15 & Chuanhsiang E (2350) & Chuanhsiang E (2350)-Chunghuonan E (540) 1st line \\
\hline & Fault 16 & Chunghuonan E (540) & Chunghuonan E (540)-Changbin E (2300) 1st line \\
\hline & Fault 17 & Chungkang E (2150) & Chungkang E (2150)-Cchungko E (2170) Nth line \\
\hline & Fault 18 & Nantou E (2400) & Nantou E (2400)-Chuanhsiang E (2350) 1st line \\
\hline & Fault 19 & Chiamin E (2500) & Chiamin E (2500)-Chungliaopei E (2480) 1st \& 2nd line \\
\hline
\end{tabular}

Tables 3 and 4 show when the bus in the Taipower grid fails, and whether the OWT connection points will recover to $90 \%$ of rated voltage in three seconds after the fault occurs [26]. According to the 
results, when an accident occurs in an adjacent offshore wind farm, the OWT connection points will recover to $90 \%$ of rated voltage in 3 seconds at accident time points 0.1 second, 0.14 second, and 0.15 second. Therefore, no matter how much the voltage dips at the OWT connection point, the OWTs shall be able to remain grid-connected for at least 0.15 seconds when an accident occurs, this is, point $\mathrm{D}$ in Figure 4 is 0.15 .

Table 3. The fault clearance time $(0.1,0.14$, and 0.15 seconds) influences on wind farms (Lutung, Luhsi, Hsienhsi, Changbin, and Tacheng) [26].

\begin{tabular}{|c|c|c|c|c|c|c|c|}
\hline \multirow{2}{*}{$\begin{array}{l}\text { Fault Scenario } \\
\qquad(161 \mathrm{kV})\end{array}$} & \multicolumn{3}{|c|}{$\begin{array}{l}\text { Fault Clearing Time } \\
\text { (seconds) }\end{array}$} & \multirow{2}{*}{$\begin{array}{c}\text { Fault Scenario } \\
(345 \mathrm{kV})\end{array}$} & \multicolumn{3}{|c|}{$\begin{array}{c}\text { Fault Clearing Time } \\
\text { (seconds) }\end{array}$} \\
\hline & 0.1 & 0.14 & 0.15 & & 0.1 & 0.14 & 0.15 \\
\hline Fault 1 & & $\mathrm{O}$ & $\mathrm{O}$ & Fault 11 & $\mathrm{O}$ & $\mathrm{O}$ & $\mathrm{O}$ \\
\hline Fault 2 & & $\mathrm{O}$ & $\mathrm{O}$ & Fault 12 & $\mathrm{O}$ & $\mathrm{O}$ & $\mathrm{O}$ \\
\hline Fault 3 & & $\mathrm{O}$ & $\mathrm{O}$ & Fault 13 & $\mathrm{O}$ & $\mathrm{O}$ & $\mathrm{O}$ \\
\hline Fault 4 & & $\mathrm{O}$ & $\mathrm{O}$ & Fault 14 & $\mathrm{O}$ & $\mathrm{O}$ & $\mathrm{O}$ \\
\hline Fault 5 & & $\mathrm{O}$ & $\mathrm{O}$ & Fault 15 & $\mathrm{O}$ & $\mathrm{O}$ & $\mathrm{O}$ \\
\hline Fault 6 & & $\mathrm{O}$ & $\mathrm{O}$ & Fault 16 & $\mathrm{O}$ & $\mathrm{O}$ & $\mathrm{O}$ \\
\hline Fault 7 & & $\mathrm{O}$ & $\mathrm{O}$ & Fault 17 & $\mathrm{O}$ & $\mathrm{O}$ & $\mathrm{O}$ \\
\hline Fault 8 & & $\mathrm{O}$ & $\mathrm{O}$ & Fault 18 & $\mathrm{O}$ & $\mathrm{O}$ & $\mathrm{O}$ \\
\hline Fault 9 & & $\mathrm{O}$ & $\mathrm{O}$ & Fault 19 & $\mathrm{O}$ & $\mathrm{O}$ & $\mathrm{O}$ \\
\hline Fault 10 & & $\mathrm{O}$ & $\mathrm{O}$ & & & & \\
\hline
\end{tabular}

Notes: O: The wind turbines voltage at the PCC recovered to $90 \%$ of the rated voltage in 3 seconds after the fault happened; X: The wind turbines voltage at the PCC unrecovered to $90 \%$ of the rated voltage in 3 seconds after the fault happened.

Table 4. The fault clearance time $(0.2,0.5$, and 0.625 seconds) effects on wind farms (Lutung, Luhsi, Hsienhsi, Changbin, and Tacheng) [26].

\begin{tabular}{ccccccc}
\hline & \multicolumn{5}{c}{ Fault Clearing Time (seconds) } \\
Fault & $\begin{array}{c}\text { Changbin, Hsienhsi, Lutung and } \\
\text { Luhsi Windfarms }\end{array}$ & \multicolumn{2}{c}{ Tacheng Windfarm } \\
\cline { 2 - 7 } & $\mathbf{0 . 2}$ & $\mathbf{0 . 5}$ & $\mathbf{0 . 6 2 5}$ & $\mathbf{0 . 2}$ & $\mathbf{0 . 5}$ & $\mathbf{0 . 6 2 5}$ \\
\cline { 2 - 7 } Fault 1 & $\mathrm{O}$ & $\mathrm{O}$ & $\mathrm{O}$ & $\mathrm{O}$ & $\mathrm{O}$ & $\mathrm{O}$ \\
Fault 2 & $\mathrm{O}$ & $\mathrm{O}$ & $\mathrm{O}$ & $\mathrm{O}$ & $\mathrm{O}$ & $\mathrm{O}$ \\
Fault 3 & $\mathrm{O}$ & $\mathrm{O}$ & $\mathrm{O}$ & $\mathrm{O}$ & $\mathrm{O}$ & $\mathrm{O}$ \\
Fault 4 & $\mathrm{O}$ & $\mathrm{O}$ & $\mathrm{O}$ & $\mathrm{O}$ & $\mathrm{O}$ & $\mathrm{O}$ \\
Fault 5 & $\mathrm{O}$ & $\mathrm{O}$ & $\mathrm{O}$ & $\mathrm{O}$ & $\mathrm{O}$ & $\mathrm{O}$ \\
Fault 6 & $\mathrm{O}$ & $\mathrm{O}$ & $\mathrm{O}$ & $\mathrm{O}$ & $\mathrm{O}$ & $\mathrm{O}$ \\
Fault 7 & $\mathrm{O}$ & $\mathrm{O}$ & $\mathrm{O}$ & $\mathrm{O}$ & $\mathrm{O}$ & $\mathrm{O}$ \\
Fault 8 & $\mathrm{O}$ & $\mathrm{O}$ & $\mathrm{O}$ & $\mathrm{O}$ & $\mathrm{O}$ & $\mathrm{O}$ \\
Fault 9 & $\mathrm{O}$ & $\mathrm{O}$ & $\mathrm{O}$ & $\mathrm{O}$ & $\mathrm{O}$ & $\mathrm{O}$ \\
Fault 10 & $\mathrm{O}$ & $\mathrm{O}$ & $\mathrm{O}$ & $\mathrm{O}$ & $\mathrm{O}$ & $\mathrm{O}$ \\
Fault 11 & $\mathrm{O}$ & $\mathrm{X}$ & $\mathrm{X}$ & $\mathrm{O}$ & $\mathrm{X}$ & $\mathrm{X}$ \\
Fault 12 & $\mathrm{X}$ & $\mathrm{X}$ & $\mathrm{X}$ & $\mathrm{X}$ & $\mathrm{X}$ & $\mathrm{X}$ \\
Fault 13 & $\mathrm{O}$ & $\mathrm{X}$ & $\mathrm{X}$ & $\mathrm{O}$ & $\mathrm{X}$ & $\mathrm{X}$ \\
Fault 14 & $\mathrm{O}$ & $\mathrm{O}$ & $\mathrm{O}$ & $\mathrm{O}$ & $\mathrm{O}$ & $\mathrm{O}$ \\
Fault 15 & $\mathrm{X}$ & $\mathrm{X}$ & $\mathrm{X}$ & $\mathrm{X}$ & $\mathrm{X}$ & $\mathrm{X}$ \\
Fault 16 & $\mathrm{X}$ & $\mathrm{X}$ & $\mathrm{X}$ & $\mathrm{X}$ & $\mathrm{X}$ & $\mathrm{X}$ \\
Fault 17 & $\mathrm{O}$ & $\mathrm{X}$ & $\mathrm{X}$ & $\mathrm{O}$ & $\mathrm{X}$ & $\mathrm{X}$ \\
Fault 18 & $\mathrm{O}$ & $\mathrm{X}$ & $\mathrm{X}$ & $\mathrm{O}$ & $\mathrm{X}$ & $\mathrm{X}$ \\
Fault 19 & $\mathrm{O}$ & $\mathrm{O}$ & $\mathrm{X}$ & $\mathrm{O}$ & $\mathrm{X}$ & $\mathrm{X}$ \\
\hline
\end{tabular}

Notes: O: The wind turbines voltage at the PCC recovered to $90 \%$ of the rated voltage in 3 seconds after the fault happened; X: The wind turbines voltage at the PCC unrecovered to $90 \%$ of the rated voltage in 3 seconds after the fault happened. 
3.2. Establishment of the Values of Point E to Point G-Aalysis of the Vltage of Ofshore Wnd Farms under Dfferent Fult Cearing Tmes

Section 3.1 has defined point $\mathrm{D}$ as 0.15 seconds, thus, the fault time simulation shall be greater than or equal to 0.15 seconds. According to [25], when the fault is the most serious three-phase short-circuit fault, the minimum voltage at the OWT connection point is obtained, i.e., the valley of voltage at the OWT connection point at fault times of 0.15 second, 0.2 second, 0.5 second, and 0.625 second occur when the three-phase short-circuit fault happens in an adjacent offshore wind farm bus. Figure 5 illustrates the wind turbines minimum PCC voltages in the TPC system for varying fault durations and scenarios [26]. Table 5 shows the minimum voltage of each wind farm at PCC. The minimum voltage of the OWTs at PCC was 0.091 p.u. when a fault happened on the shore for offshore wind farms. The extent of each voltage sag was especially large when the fault happened due to the OWFs were near to the onshore PCC voltages. Therefore, the minimum voltage must be 0.09 p.u. at E, and the length of time must be 0.625 seconds from $E$ to $G$ to prevent the offshore turbines disconnection with the power grid without impacting the stability of the power system. As shown in Figure 4, the points $\mathrm{A} \rightarrow \mathrm{C} \rightarrow \mathrm{D} \rightarrow \mathrm{E} \rightarrow \mathrm{G} \rightarrow \mathrm{H} \rightarrow \mathrm{I}$ were linked to constitute the proposed LVRT curve in this study (Figure 6).

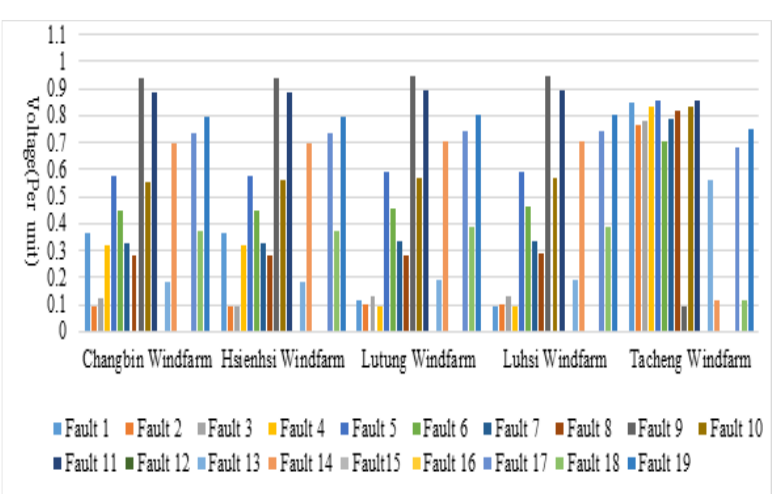

(a)

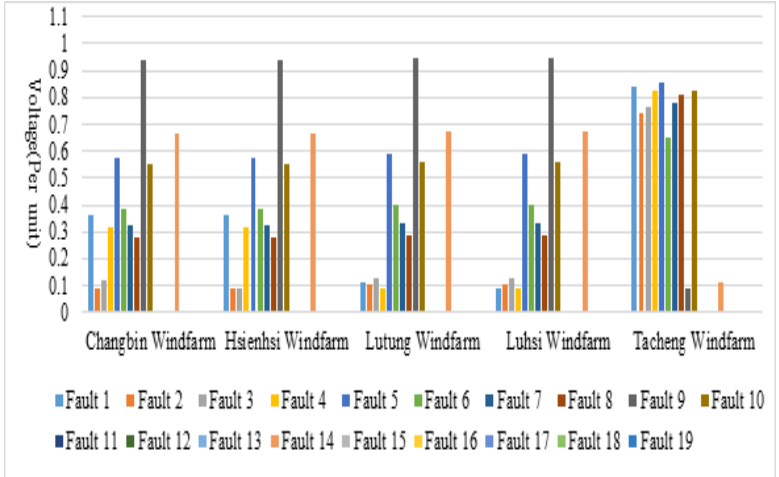

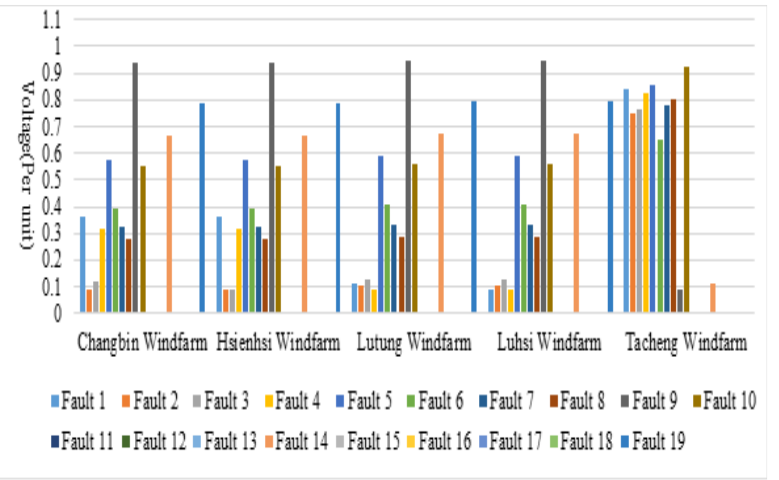

(b)

(c)

Figure 5. Minimum voltage of OWTs: (a) 0.2 seconds at the fault time point; (b) 0.5 seconds at the fault time point; (c) 0.625 seconds at the fault time point [26].

Table 5. Minimum voltage value of offshore wind farm connection point under different fault times.

\begin{tabular}{ccc}
\hline Offshore Wind Farms & Fault Location & Offshore Wind Farm Voltage (p.u.) \\
\hline Changbin & Changbin H & 0.091 \\
Hsienhsi & Hsienhsi H & 0.091 \\
Lutung & Lutung H & 0.091 \\
Luhsi & Luhsi H & 0.091 \\
Tacheng & Tacheng H & 0.091 \\
\hline
\end{tabular}




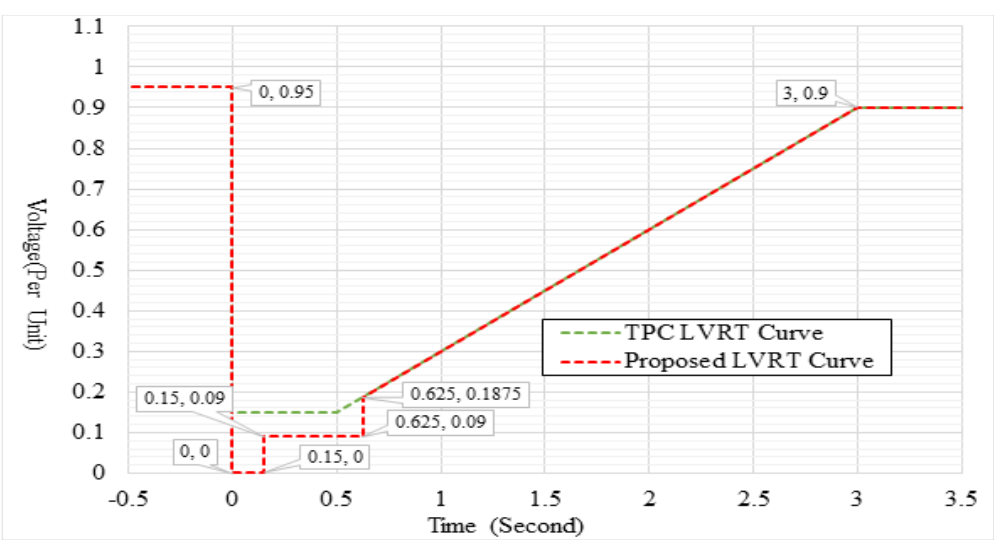

Figure 6. The proposed LVRT curve (with values of each point) versus TPC LVRT curve.

Figure 6 depicts the proposed LVRT curve, which is detailed as follows:

$>$ The turbine should proceed to operate for a minimum of 0.15 seconds when the PCC voltage of the wind turbines sags to 0 p.u.

$>$ The turbine should proceed to operate for a minimum of 0.475 seconds when the PCC voltage of the wind turbines sags to 0.09 p.u.

$>$ When the PCC voltage of the wind turbine exceeds the proposed LVRT curve (shown as a red dotted line) during the voltage sag, the turbine remains in operation.

\section{Fault Analysis of the OWTs under Different LVRT Curves}

This section compares the effects of the proposed LVRT curve and the TPC LVRT curve on the grid performance, namely the transient stability analysis, when three-phase short circuit faults occurred in the $161 \mathrm{kV}$ and $345 \mathrm{kV}$ buses; this section then reveals the advantage of the proposed LVRT curve over the TPC LVRT curve. This section analyzes the effects of the two aforementioned specifications of LVRT on the Taipower system at different fault points and fault clearance times when three-phase short circuit faults occurred with subsequent circuit trips. This system involved the OWTs with a total power generation capacity of 520 MW coupled with the Lutung, Luhsi, Hsienhsi, Changbin, and Tacheng distribution substations. The Changbin $\mathrm{H}$ (2301) substation was designated as the fault point, and the Rth loop transmission line between Changbin H (2301) and Lutung H (5809) was determined as the tripping circuit in investigating the real power and PCC voltage changes of the turbines under the two specifications of LVRT during and after the fault occurrence. The time points were defined as follows: at 1 seconds of the fault occurrence; the circuit tripped at the seventh cycle (approx. 1.1166 seconds); the fault clearance at the twelfth cycle (1.2 seconds).

According to Figure 7, when the fault occurred in the Changbin $\mathrm{H}$ substation, if the TPC LVRT curve was implemented in the OWTs, then all the offshore turbines in the Changbin block tripped at 0.08 seconds, as shown in Figure 7a. This was because the turbines were close in distance to the fault point, leading their PCC voltage to fall below 0.15 p.u. when the fault occurred. Conversely, when the proposed LVRT curve was adopted, none of the turbines tripped, as shown in Figure $7 \mathrm{~b}$. According to Figure 8, when faults occurred, the voltage dips in the Lutung H (Figure 8c) and Luhsi H (Figure 8d) substations were more severe if the TPC LVRT curve was adopted than if the proposed LVRT curve was adopted because of the circuit trips in the OWTs; moreover, the times for voltage recovery to 0.9 p.u. after fault clearance were longer if the TPC LVRT curve was adopted, and the disturbance to the system was higher. 


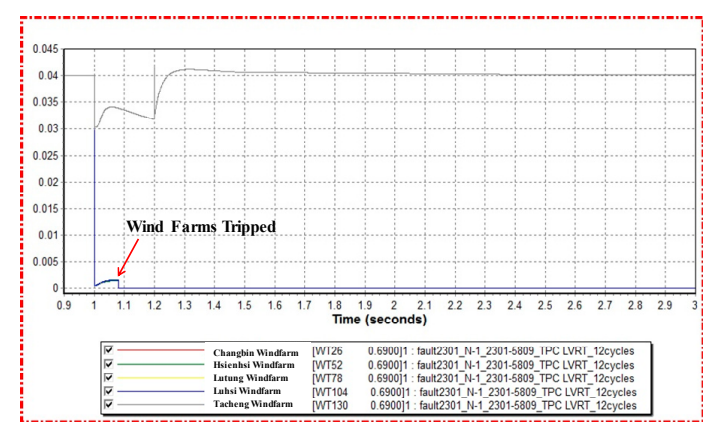

(a)

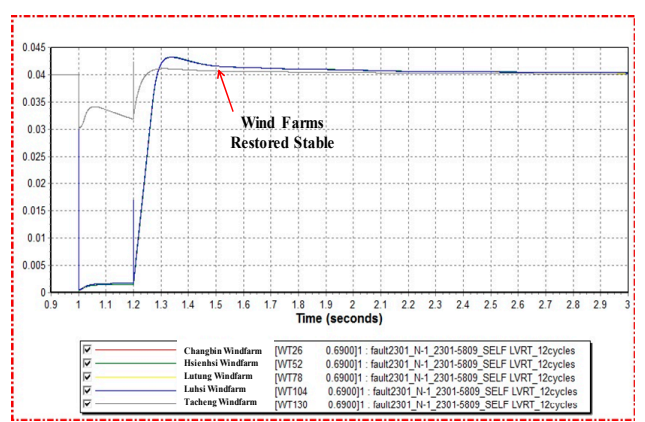

(b)

Figure 7. When Changbin H occurs fault: (a) Real power of the turbine under the TPC LVRT curve during fault occurrence at the Changbin $\mathrm{H}$ substation; (b) Real power of the turbine under the proposed LVRT curve during fault occurrence at the Changbin $\mathrm{H}$ substation.

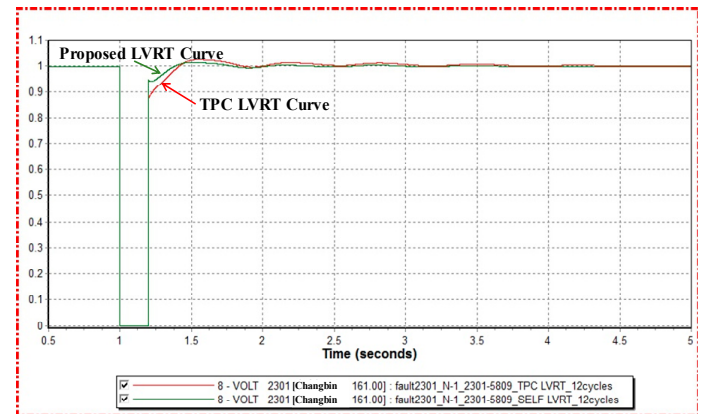

(a)

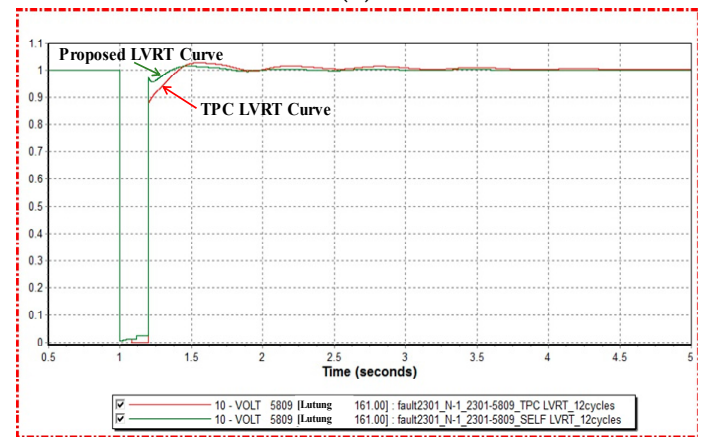

(c)

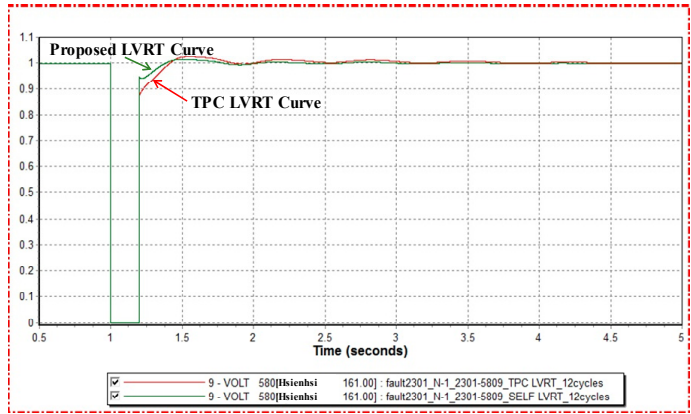

(b)

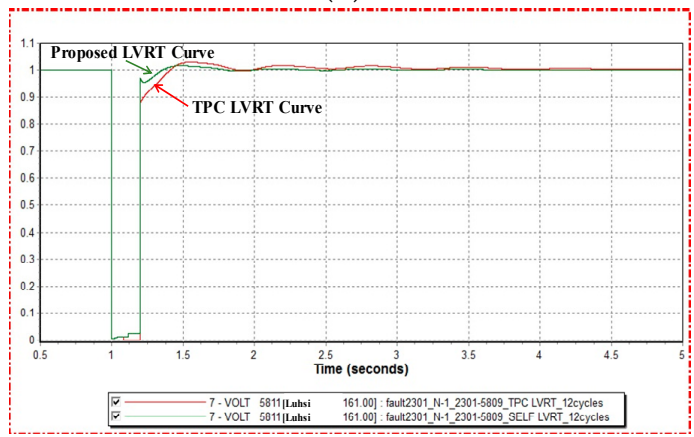

(d)

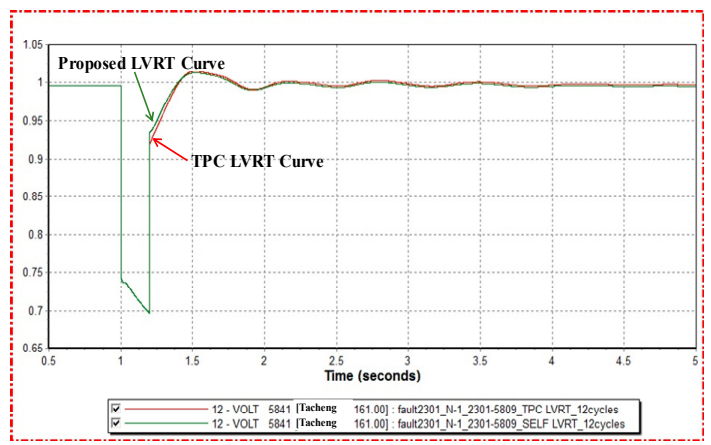

(e)

Figure 8. When Changbin H occurs fault: PCC voltage changes in the turbine under the TPC curve and the proposed LVRT curve: (a) Changbin H Voltage; (b) Hsienhsi H Voltage; (c) Lutung H Voltage; (d) Luhsi H Voltage; (e) Tacheng H Voltage. 


\section{Conclusions}

This paper merges the target of 520 MW offshore wind power, as planned by Taiwan for 2020, into the Taipower Changbin district (Lutung, Luhsi, Hsienhsi, and Changbin distribution substations) and Changbin district (Tacheng distribution substation), based on the content specified of the TPC transmission system planning criteria and technical key points, as combined with the actual Taipower system, and varying fault scenarios and fault times are considered in the analysis, in order to formulate a new LVRT. This LVRT curve was analyzed and compared with the current TPC LVRT curve regarding effects on the transient stability in the system. According to the results, applying the proposed LVRT curve in the wind turbines avoided the disconnection of the turbines and the power system, reduced the PCC voltage dip during fault occurrences, lessened the disturbances caused by faults, shortened the time of voltage recovery to 0.9 p.u., and enhanced the operational stability between the turbines and the grids. This study may act as a reference for power companies for their LVRT curve revision in the future.

Author Contributions: S.D.L conceived of the presented idea, designed the simulation cases and wrote this article; M.-H.W. supervised the findings of this work; C.-Y.T performed the simulations; all authors provided critical feedback and helped shape the research, analysis and manuscript.

Acknowledgments: The authors gratefully acknowledge the financial support of the National Chin-Yi University of Technology, R.O.C. through its grants NCUT 19-R-CE-017 and also express their gratitude to the Power Dispatching Department of Taiwan Power Company for providing much precious advice and help, so as to this research could be completed successfully.

Conflicts of Interest: The authors declare no conflict of interest.

\section{References}

1. Global Wind Energy Council (GWEC). Global Wind Statistics. 2017. Available online: https: / / www.google.com.hk/url?sa=t\&rct=j\&q=\&esrc=s\&source=web\&cd=1\&ved=

2ahUKEwi7qqTm66PhAhWMGaYKHdZEBiMQFjAAegQIABAB\&url=https\%3A\%2F\%2Fgwec.net\% 2Fwp-content\%2Fuploads\%2Fvip\%2FGWEC_PRstats2017_EN-003_FINAL.pdf\&usg=AOvVaw3kG04vWc107qaCoVeVH5C (accessed on 14 February 2018).

2. Executive Yuan, Four-Year Plan for Promoting wind Power Generation-Clean Energy is Emerging. 2018. Available online: https:/ / www.ey.gov.tw/Page/5A8A0CB5B41DA11E/ef93b5c1-85ea-4b5f-ac55-f460d9204258 (accessed on 26 March 2019).

3. Dobson, I.; Chiang, H.D.; Thorp, J.S.; Fekih-Ahmed, L. A model of voltage collapse in electric power systems. In Proceedings of the 27th IEEE Conference, Austin, TX, USA, 7-9 December 1988. [CrossRef]

4. Park, C.H.; Jang, G. Voltage quality assessment considering low voltage ride-through requirement for wind turbines. IET Gener. Transm. Distrib. 2016, 10, 4205-4214. [CrossRef]

5. Fandi, G.; Ahmad, I.; Igbinovia, F.O.; Muller, Z.; Tlusty, J.; Krepl, V. Voltage Regulation and Power Loss Minimization in Radial Distribution Systems via Reactive Power Injection and Distributed Generation Unit Placement. Energies 2018, 11, 1399. [CrossRef]

6. Krepl, V.; Ahmad, I.; Igbinovia, F.O.; Ivanova, T.; Fandie, S.; Muller, Z.; Tlusty, J. Design of an Emergency Energy System for a City Assisted by Renewable Energy, Case Study: Latakia, Syria. Energies 2018, 11, 3138.

7. Wu, Y.; Yang, W.; Hu, Y.; Dzung, P.Q. Frequency Regulation at a Wind Farm Using Time-Varying Inertia and Droop Controls. IEEE Trans. Ind. App. 2019, 55, 213-224. [CrossRef]

8. Lee, J.; Jang, G.; Muljadi, E.; Blaabjerg, F.; Chen, Z.; Kang, Y.C. Stable short-term frequency support using adaptive gains for a DFIG-based wind power plant. IEEE Trans. Energy Convers. 2016, 31, 1068-1079. [CrossRef]

9. Taiwan Power Company, Renewable Energy Power Generation System Interconnection Technology Act. 2016. Available online: http:/ / www.taipower.com.tw (accessed on 6 October 2016).

10. Weck, K.H. Low-Voltage Ride Through (LVRT) Requirements and Testing. Research Association for Electrical Systems and Electricity. 2009. Available online: https://wenku.baidu.com/view/ 5abdf46a1611cc7931b765ce05087632311274ee.html?re=view (accessed on 6 January 2009). 
11. Iov, F.; Hansen, A.D.; Sørensen, P.; Cutululis, N.A. Mapping of Grid Faults and Grid Codes; Risø National Laboratory: Roskilde, Danmark, 2007.

12. E.ON Netz GmbH, Grid Code-High and Extra High Voltage. Available online: http:/ /www.pvupscale. org/IMG/pdf/D4_2_DE_annex_A-3_EON_HV_grid_connection_requirements_ENENARHS2006de.pdf (accessed on 1 April 2006).

13. Tsili, M.; Papathanassiou, S. A review of grid code technical requirements for wind farms. IET Renew. Power Gener. 2009, 3, 308-332. [CrossRef]

14. Benbouzid1, M.; Muyeen, S.M.; Khoucha1, F. An Up-to-Date Review of Low-Voltage Ride-Through Techniques for Doubly-Fed Induction Generator-Based Wind Turbines. Int. J. Energy Convers. 2015, 3, 1-9.

15. The Grid Code. Available online: https://www.nationalgrideso.com/sites/eso/files/documents/29446Issue \%203\%20Revision\%2024\%20-\%2019\%20November\%202007.pdf (accessed on 19 November 2007).

16. Wind turbines connected to grids with voltages below $100 \mathrm{kV}$, Regulation TF 3.2.6. Available online: https://en.energinet.dk/-/media/1196EE254B854D21AD88B2DC813BFEA9.pdf?la=en\&hash= ACF6DBC39FEF7340E206E48BE4845941519CAE97 (accessed on 19 May 2007).

17. Wind turbines connected to grids with voltages above $100 \mathrm{kV}$, Regulation TF 3.2.5. Available online: http:/ / bibing.us.es/proyectos/abreproy/70370/descargar_fichero/22.+Wind+Turbines+Connected+to+ Grids+with+Voltage+above100+kV.pdf (accessed on November 2004).

18. Joos, G. Review of grid codes. In Proceedings of the first International Conference Integration of Renewable Energy and DER (IRED 04), Brussels, Belgium, 1-3 December 2004.

19. Wu, T.S. Analysis and Comparison of Low Voltage Ride Through Capability of Wind Power Generators. Master' Thesis, National Sun Yat-sen University, Kaohsiung, Taiwan, September 2013. (In Chinese)

20. Chen, Y.J. Analysis of Low Voltage Ride Through Capability of Different Off-shore Wind Farm Collection Schemes. Master' Thesis, National Sun Yat-sen University, Kaohsiung, Taiwan, June 2012. (In Chinese)

21. Lin, X.H. A Study on Low Voltage Ride-through Capability Improvement for Doubly Fed Induction generator. Master' Thesis, National Sun Yat-sen University, Kaohsiung, Taiwan, July 2010. (In Chinese)

22. Tseng, Y.Y. Study on the Low Voltage Ride through Characteristics of Wind Power Generator. Master' Thesis, National Taiwan University of Science and Technology, Taipei, Taiwan, June 2009. (In Chinese)

23. Thousand Wind Turbines Project, Bureau of Energy, Ministry of Economic Affairs, R.O.C. Available online: http:/ / www.twtpo.org.tw / professio\$ \delimiter"026E30F\$=nal/ count.aspx (accessed on 1 October 2018).

24. Kazachkov, Y.; Altman, R.; Senthil, J.; Patil, K. PSS®E Wind Modeling Package for GE 1.5/1.6/2.5/2.75/4.0 MW Wind Turbines User Guide; Siemens: Berlin, Germany, 2011.

25. Taiwan Power Company, Taiwan Power Company Transmission System Planning Guidelines. Available online: http:/ / www.taipower.com.tw (accessed on 1 April 2013).

26. Lu, S.D.; Wang, M.H.; Tai, C.Y.; Tsou, M.C.; Gu, F.C. Formulation of Low Voltage Ride-Through Curve Considering Offshore Wind Farms Integrated into an Islanding Power System - A Case Study in Taiwan. In Proceedings of the 2018 International Symposium on Computer, Consumer and Control (IS3C), Taichung, Taiwan, 6-8 December 2018. [CrossRef]

(C) 2019 by the authors. Licensee MDPI, Basel, Switzerland. This article is an open access article distributed under the terms and conditions of the Creative Commons Attribution (CC BY) license (http://creativecommons.org/licenses/by/4.0/). 